\title{
Response of microbial activity and biomass to soil salinity when supplied with glucose and cellulose
}

\author{
B. Elmajdoub ${ }^{1,2^{*}}$, P. Marschner ${ }^{1}$, \\ ${ }^{1}$ School of Agriculture, Food and Waite Research Institute, The University of Adelaide, Adelaide SA 5005, \\ Australia ${ }^{2}$ Biotechnology Research Centre, Libya, P.O. Box 30313, Tripoli, Libya \\ "Corresponding author: Bannur.Elmajdoub@adelaide.edu.au
}

\begin{abstract}
Two incubation experiments were carried out to determine the impact of salinity on microbial activity and biomass when organic carbon is supplied as different proportions of glucose and cellulose or when glucose and cellulose were added every 2 weeks in different order. The first experiment was conducted with a non-saline soil and two saline soils (ECe 11 and $43 \mathrm{dS} \mathrm{m}^{-1}$ ) amended with $5 \mathrm{~g} \mathrm{C} \mathrm{kg}^{-1}$ as different percentages of glucose and cellulose: glucose: $100 \%$ and $0-20 \%$ and cellulose: $0-100 \%$. In the second experiment a non-saline loamy sand soil was used which was salinized to ECe 12.5 and $37.4 \mathrm{dS} \mathrm{m}^{-1}$. The $\mathrm{C}$ form was maintained or changed over time by addition of $1.5 \mathrm{~g} \mathrm{C} \mathrm{kg}^{-1}$ every two weeks as glucose or cellulose. In Experiment 1, mixing glucose with cellulose increased cumulative respiration compared to cellulose alone. Cumulative respiration increased with increasing proportion of glucose in the combined treatments with glucose $>2.5 \%$. With $100 \%$ glucose, cumulative respiration was significantly lower than in the non-saline soil only in EC43. But with $100 \%$ cellulose and all combined treatments, cumulative respiration was significantly lower than in the non-saline soil in EC11 and EC43. Cumulative respiration did not differ between EC11 and EC43 with 100\% cellulose but decreased significantly in the mixed treatments except with $10 \%$ glucose. In Experiment 2, cumulative respiration in the first period (0-14) was always higher with glucose than with cellulose; it decreased with increasing EC. The impact of salinity was smaller when $\mathrm{C}$ was added repeatedly compared to a single addition. Cumulative respiration increased when glucose was added after cellulose addition. In conclusion, mixing small amounts of glucose with cellulose could make microbes more sensitive to salinity compared to $100 \%$ cellulose. Further, maintaining high $\mathrm{C}$ availability with repeated $\mathrm{C}$ addition reduces the negative impact of salinity on soil microbes.
\end{abstract}

Keywords: Cellulose, glucose, microbial biomass, respiration, salinity 


\section{Introduction}

Globally $831 \mathrm{M}$ ha of land is affected by salt (MartinezBeltran and Manzur, 2005) which is a threat to ecosystems particularly in arid and semi-arid regions. Salt accumulation increases the osmotic potential of the soil solution and thereby reduces water availability to plants and microbes. Further, salinity can affect physiological processes by ion toxicity and ion imbalance (Klados and Tzortzakis, 2014; Kahlaoui et al., 2011; Munns and Tester, 2008). As a result, saline soils are characterized by low organic matter content and reduced organic matter turnover due to poor plant growth and low microbial biomass and activity (e.g. Muhammad et al., 2006; Tripathi et al., 2006). In addition, salinity changes the microbial community composition because microbial genotypes differ in their ability to adapt to salt stress (Nelson and Mele, 2007; Pankhurst et al., 2001). Several studies have suggested that bacteria are more tolerant to salinity than fungi (Chowdhury et al., 2011b; Pankhurst et al., 2001), however Wichern et al. (2006) found that bacteria are more sensitive to salinity than fungi. In non-saline soil microbial growth is often limited by the availability of organic carbon (C) (De Nobili et al., 2001). The organic $\mathrm{C}$ demand of microbes in saline soils may be higher than that of microbes in non-saline soils because adaptation to osmotic stress requires a high amount of energy to synthesise organic osmolytes (Hagemann, 2011; Oren, 1999). Addition of organic $\mathrm{C}$ to saline soils could allow microbes to synthesise osmolytes and thereby increase their adaptation to salt stress. Previous studies have shown that the response of microbial activity (respiration) to salinity (high osmotic potential) depended on the amount of substrate available with microbial activity being less sensitive to salinity when $\mathrm{C}$ availability is high (Elmajdoub and Marschner, 2013; Wichern et al., 2006).
In a previous study (Elmajdoub and Marschner, 2013) we showed that the response of microbial activity (respiration) to salinity also varied with organic $\mathrm{C}$ form. Cumulative respiration decreased gradually with increasing salinity (electrical conductivity in the saturated paste extract (ECe 1, 11 and $43 \mathrm{dS}$ $\mathrm{m}^{-1}$ ) when $\mathrm{C}$ was supplied as glucose, whereas it decreased sharply from non-saline to saline soils when $\mathrm{C}$ was added as cellulose. This may be due to the fact that glucose can be utilised rapidly by most microorganisms whereas cellulose is decomposed more slowly by fewer microbes capable of releasing cellulase (Sylvia et al., 2005). Thus, sensitivity of a few genotypes to salinity will have little impact on the utilisation of glucose, but can strongly reduce cellulose decomposition. However, little is known about the response of soil microbial activity and biomass to salinity when glucose and cellulose are either supplied as different proportions or when the $\mathrm{C}$ form changes over time. To address these knowledge gaps we conducted two experiments. The aim of Experiment 1 was to determine the impact of salinity on microbial activity and biomass when $\mathrm{C}$ is supplied as different proportions of glucose and cellulose. Experiment 2 was designed to assess the response of soil microbial activity, biomass and community structure to increasing salinity when the C form changes repeatedly. We hypothesised that (i) microbial activity and biomass will decrease more rapidly with salinity compared to glucose alone as the proportion of glucose in the mixture with cellulose decreases, becoming similar to that with cellulose alone (Experiment 1), (ii) compared to a single addition, the reduction of respiration by salinity will be smaller with repeated $\mathrm{C}$ addition due to increasing $\mathrm{C}$ supply irrespective of the form in which $\mathrm{C}$ is supplied (glucose or cellulose) (Experiment 2), 
and (iii) microbial activity will be little affected by medium salinity when glucose is added whereas it will be reduced with cellulose addition.

\section{Materials and Methods}

\subsection{Experiment 1 (different proportions of glucose and cellulose)}

Three sandy clay loam soils (one non-saline and two saline) were collected at Monarto $\left(35^{\circ} 05^{\prime} \mathrm{S}\right.$ and $139^{\circ} 06^{\prime}$ E), South Australia, which is characterised by the Mediterranean climate. The soils were airdried and sieved to $<2 \mathrm{~mm}$ (Table 1). Electrical conductivity, sodium absorption ratio (SAR) and $\mathrm{pH}$ were determined in a 1:5 soil: water ratio after $1 \mathrm{~h}$ endover-end shaking at $25^{\circ} \mathrm{C}$ (Rayment and Higginson, 1992). The $\mathrm{EC}_{1: 5}$ of the soils was $0.1,1.1$ and $4.2 \mathrm{dS}$ $\mathrm{m}^{-1}$ which corresponds to an EC of a saturated paste extract (ECe) of 1, 11, and $43 \mathrm{dS} \mathrm{m}^{-1}$ and hereafter referred to as EC1, EC11 and EC43. The $\mathrm{EC}_{1: 5}$ was converted to $\mathrm{ECe}$ using the equation: $\mathrm{ECe}=(14.0-$ $0.13 \times$ clay \%) $\times \mathrm{EC}_{1: 5}($ Rengasamy, 2006). The soils were saline-sodic, but did not show the dispersive impact of sodicity due to the high salt concentration in the soil solution which causes the soil particles to flocculate (Shainberg and Letey, 1984).

Reverse osmosis (RO) water was added to adjust the water content to $30 \%$ of maximum water holding capacity (WHC) after which the soils were preincubated at $25{ }^{\circ} \mathrm{C}$ for 10 days before the start of the experiment to reactivate and stabilize microbial activity after rewetting of the air-dried soils (Butterly et al., 2010).

To test the range of proportions of glucose and cellulose to be used in the main experiment, a preliminary experiment was conducted using a rate of $5 \mathrm{~g} \mathrm{C} \mathrm{kg}^{-1}$ as five different proportions of glucose $(\mathrm{G})$ and cellulose $(\mathrm{Ce}): 25 \% \mathrm{G}+75 \% \mathrm{Ce}, 50 \% \mathrm{G}+50 \% \mathrm{Ce}$,
$75 \% \mathrm{G}+25 \% \mathrm{Ce}, 100 \% \mathrm{G}, 100 \% \mathrm{Ce}$ and a control without $\mathrm{C}$ addition. Soil respiration was measured over 21 days. There were only small differences in cumulative respiration among the different proportions of glucose which all showed higher values than the $100 \%$ cellulose treatment. This suggested that even at the lowest glucose proportion ( $25 \%$ of the $\mathrm{C}$ added), sufficient $\mathrm{C}$ was present as glucose to satisfy the requirement of the microbes during the experiment. Calculations based on soil respiration indicated that little, if any, cellulose $\mathrm{C}$ had been decomposed. Therefore, in the main experiment (with $5 \mathrm{~g} \mathrm{C} \mathrm{kg}^{-1}$ ), smaller proportions of glucose ( 2.5 to $20 \%$ ) were used. The treatments were $100 \% \mathrm{Ce}, 2.5 \% \mathrm{G}+97.5 \% \mathrm{Ce}$, $5 \% \mathrm{G}+95 \% \mathrm{Ce}, \quad 10 \% \mathrm{G}+90 \% \mathrm{Ce}, \quad 20 \% \mathrm{G}+80 \% \mathrm{Ce}$ and $100 \% \mathrm{G}$. An unamended control was also included. Nitrogen and phosphorus were added as $\left(\mathrm{NH}_{4}\right)_{2} \mathrm{SO}_{4}$ and $\mathrm{KH}_{2} \mathrm{PO}_{4}$ to achieve a $\mathrm{C} / \mathrm{N}$ ratio of 20 and a $\mathrm{C} / \mathrm{P}$ ratio of 200 , which are considered to be sufficient for growth of the majority of heterotrophic microbes (Sylvia et al., 2005). Glucose, $\left(\mathrm{NH}_{4}\right)_{2} \mathrm{SO}_{4}$ and $\mathrm{KH}_{2} \mathrm{PO}_{4}$ were added as solutions, cellulose as powder (Sigma cell cellulose, type 20 ). The unamended soils received only RO water. The final water content was $50 \%$ of WHC which is optimal for microbial activity in soils of this texture (Setia et al., 2011). The nutrient addition did not significantly change the EC (data not shown). After amendment, the soils were mixed immediately to ensure homogeneity of wetting and nutrient distribution. Then $30 \mathrm{~g}$ of soil was added to PVC cores with radius $1.85 \mathrm{~cm}$ and height $5 \mathrm{~cm}$ and a nylon mesh base $(0.75 \mu \mathrm{m}$, Australian Filter Specialist) and packed to a bulk density of $1.4 \mathrm{~g} \mathrm{~cm}^{-1}$.

The cores were placed individually into $1 \mathrm{~L}$ glass jars with gas tight lids equipped with septa to allow quantification of the headspace $\mathrm{CO}_{2}$ concentration. The jars were incubated in the dark at $25^{\circ} \mathrm{C}$ for three weeks during which $\mathrm{CO}_{2}$ emission was measured continuously. Separate cores were destructively sampled on days 2, 7 and 21 to measure microbial biomass $\mathrm{C}$ (MBC). 
Table 1. Physical and chemical properties of the soils used in Experiment 1

\begin{tabular}{|c|c|c|c|c|c|c|c|c|c|c|c|}
\hline $\begin{array}{c}\text { Soil } \mathrm{EC}_{15} \\
\mathrm{dS} \mathrm{m}^{-1}\end{array}$ & $\mathrm{pH}$ & SAR & $\begin{array}{c}\mathrm{EC}_{\mathrm{e}} \\
\mathrm{dS} \mathrm{m}^{-1}\end{array}$ & $\begin{array}{c}\% \\
\text { sand }\end{array}$ & $\begin{array}{c}\% \\
\text { clay }\end{array}$ & $\begin{array}{l}\% \\
\text { silt }\end{array}$ & $\begin{array}{l}\text { WHC } \\
\mathrm{gg}^{-1}\end{array}$ & $\begin{array}{c}\text { Bulk } \\
\text { density }\end{array}$ & $\begin{array}{l}\text { TOC } \\
\mathrm{g} \mathrm{kg}^{-1}\end{array}$ & $\begin{array}{l}\text { Total P } \\
\mathrm{g} \mathrm{kg}^{-1}\end{array}$ & $\begin{array}{c}\text { Total } \\
\mathrm{N}\end{array}$ \\
\hline & $1: 5$ & & & & & & & $\mathrm{~g} \mathrm{~cm}^{-3}$ & & & $\mathrm{~g} \mathrm{~kg}^{-1}$ \\
\hline 0.1 & 8.4 & 0.1 & 1 & 57,0 & 25,5 & 17,5 & 0.36 & 1.40 & 11.8 & 0.68 & 0.28 \\
\hline 1.1 & 8.9 & 12.6 & 11 & 60.0 & 27.5 & 12.5 & 0.38 & 1.40 & 5.8 & 0.36 & 0.20 \\
\hline 4.2 & 8.8 & 20.4 & 43 & 58.5 & 29.5 & 12.0 & 0.40 & 1.39 & 7.3 & 0.37 & 0.21 \\
\hline
\end{tabular}

\subsection{Experiment 2 (change of $C$ form over time)}

In this experiment, a non-saline soil was adjusted to different EC levels by adding different amounts of salt to avoid the differences in organic matter and nutrient concentrations among the soils in Experiment 1.

A non-saline loamy sand was collected from $0-20 \mathrm{~cm}$ depth at Monarto, South Australia (sand 83\%, clay $12 \%$, silt $5 \%, \mathrm{EC}_{1: 5} 0.05 \mathrm{dS} \mathrm{m}^{-1}, \mathrm{pH} 7.5$, total organic C $6.2 \mathrm{~g} \mathrm{~kg}^{-1}$, total $\mathrm{N} 0.1 \mathrm{~g} \mathrm{~kg}^{-1}$, bulk density $1.57 \mathrm{~g} \mathrm{~cm}^{-}$ ${ }^{3}$, water holding capacity (WHC) $170 \mathrm{~g} \mathrm{~kg}^{-1}$ ). The soil was air-dried and sieved to $<2 \mathrm{~mm}$.

The soil was adjusted to different salinity levels by adding $\mathrm{NaCl}\left(0,3.05\right.$ and $\left.9.25 \mathrm{~g} \mathrm{~kg}^{-1}\right)$ to achieve $\mathrm{EC}_{1: 5}$ $0.05,1$ and $3 \mathrm{dS} \mathrm{m}^{-1}$ respectively. This corresponds to $\mathrm{EC}_{\mathrm{e}} 0.6,12.5$ and $37.4 \mathrm{dS} \mathrm{m}^{-1}$ hereafter referred to as EC0.6, EC12.5 and EC37.4. These EC levels were chosen based on previous experiments to achieve moderate $\left(12.5 \mathrm{dS} \mathrm{m}^{-1}\right)$ and strong (37.4 $\mathrm{dS} \mathrm{m}^{-1}$ ) reduction of respiration. Nitrogen and $\mathrm{P}$ were added as $\left(\mathrm{NH}_{4}\right)_{2} \mathrm{SO}_{4}$ and $\mathrm{KH}_{2} \mathrm{PO}_{4}$ to achieve a $\mathrm{C} / \mathrm{N}$ ratio of 20 and a $\mathrm{C} / \mathrm{P}$ ratio of 200 based on the total amount of $\mathrm{C}$ added. $\mathrm{NaCl},\left(\mathrm{NH}_{4}\right)_{2} \mathrm{SO}_{4}$ and $\mathrm{KH}_{2} \mathrm{PO}_{4}$ were dissolved in $\mathrm{RO}$ water and mixed into the soil to achieve a water content of $65 \%$ of WHC. As in Experiment 1, the nutrient additions did not significantly influence the EC.

The moist soils were pre-incubated at $25^{\circ} \mathrm{C}$ for 18 days before the start of the experiment to revive and stabilise microbial activity. The longer pre-incubation was chosen to allow the microbes to adjust to the different EC levels. A preliminary experiment was conducted to investigate the effect of water content on cumulative respiration in the non-saline soil. The WHC was adjusted between $20 \%$ and $80 \%$ with $\mathrm{RO}$ water in soil amended with $1.5 \mathrm{~g} \mathrm{C} \mathrm{kg}^{-1}$ as glucose and respiration was measured over 10 days. Cumulative respiration was maximal at $40-75 \%$ of WHC with no significant differences among these water contents (data not shown). Therefore in this experiment the water content was increased by $5 \%$ every two weeks from $65 \%$ to $75 \%$ of WHC to allow addition of soluble glucose every two weeks. In the unamended control (no $\mathrm{C}$ addition) and treatments where cellulose powder was added, the equivalent amount of RO water was added. After the 18-day preincubation the soils were amended with $1.5 \mathrm{~g} \mathrm{C} \mathrm{kg}^{-1}$ as glucose or cellulose. Carbon was added again on days 15 and 29, so that the total $\mathrm{C}$ addition was $4.5 \mathrm{~g} \mathrm{C} \mathrm{kg}^{-1}$. There were six $\mathrm{C}$ treatments in which the $\mathrm{C}$ form was maintained or changed every 2 weeks: $\mathrm{Ce}+\mathrm{Ce}+\mathrm{Ce}$, $\mathrm{G}+\mathrm{G}+\mathrm{G}, \mathrm{Ce}+\mathrm{Ce}+\mathrm{G}, \mathrm{G}+\mathrm{Ce}+\mathrm{Ce}, \mathrm{G}+\mathrm{Ce}+\mathrm{G}, \mathrm{Ce}+\mathrm{G}+\mathrm{Ce}$. On day 0 , the soils were mixed with glucose or cellulose and then $30 \mathrm{~g}$ of soil was added to PVC cores and adjusted to a bulk density of $1.57 \mathrm{~g} \mathrm{~cm}^{-3}$. The cores were placed individually in $1 \mathrm{~L}$ glass jars and incubated in dark at $25^{\circ} \mathrm{C}$ for 42 days. Respiration was measured over 42 days. Every two weeks, C was 
added, mixed thoroughly with the soil and the bulk density re-adjusted. The unamended control received the same amount of water and was mixed and adjusted similarly. During the 14-day incubation between $\mathrm{C}$ additions, the soil water content was checked by weight and RO water was added if necessary. Destructive samples for microbial biomass C (MBC) were carried out on days $0,14,28$ and 42. Microbial community structure was determined on days 0 and 42. The soil samples for community structure were stored at $-20^{\circ} \mathrm{C}$ before PLFA extraction.

\subsection{Measurements}

Soil total organic $\mathrm{C}, \mathrm{N}$ and $\mathrm{P}$ were measured by standard methods. Soil respiration was determined by measuring the $\mathrm{CO}_{2}$ concentration in the headspace of each jar using a Servomex 1450 infra-red gas analyser (Servomex, UK) as described in Setia et al. (2011). After each measurement (t1), the jars were vented to refresh the headspace using a fan, and then resealed followed by determination of the $\mathrm{CO}_{2}$ concentration ( $\mathrm{t} 0$ ). The $\mathrm{CO}_{2}$ evolved during a given interval was calculated as the difference in $\mathrm{CO}_{2}$ concentration between $\mathrm{t} 1$ and t0. Linear regression based on injection of known amounts of $\mathrm{CO}_{2}$ in the jars was used to define the relationship between $\mathrm{CO}_{2}$ concentration and detector reading. The respiration rates [in $\mathrm{mg} \mathrm{CO}_{2}-\mathrm{C}$ (g soil and day) $)^{-1}$ ] were added to calculate cumulative respiration over 21 days in Experiment 1. In Experiment 2, cumulative respiration was calculated separately for each 14-day period after $\mathrm{C}$ addition (days 0-14, 15-28 and 29-42).

Microbial biomass $\mathrm{C}$ (MBC) was determined after destructive sampling by fumigation extraction (Vance et al., 1987) as described by Anderson and Ingram (1993) using two subsamples of $5 \mathrm{~g}$. One subsample was fumigated with ethanol-free chloroform for 24 $h$ at $25^{\circ} \mathrm{C}$ in sealed desiccators; the non-fumigated subsample was kept at $4^{\circ} \mathrm{C}$ during fumigation. After removal of the chloroform, fumigated and nonfumigated subsamples were extracted with $0.5 \mathrm{M}$ $\mathrm{K}_{2} \mathrm{SO}_{4}$ (1:4 soil to solution ratio). Dissolved organic C in the extracts was determined by titration with 0.033 $\mathrm{M}$ acidified $\left(\mathrm{NH}_{4}\right)_{2} \mathrm{Fe}\left(\mathrm{SO}_{4}\right)_{2} \cdot 6 \mathrm{H}_{2} \mathrm{O}$ after dichromate oxidation (Anderson and Ingram 1993). Microbial biomass $\mathrm{C}$ was calculated from the difference between the fumigated and non-fumigated samples multiplied by 2.64 (Vance et al., 1987).

Microbial community structure was determined by phospholipid fatty acid (PLFA) analysis. PLFAs were extracted from $4 \mathrm{~g}$ frozen soil based on Frostegård et al. (1993) using a solvent of chloroform, methanol and citrate 1:2:0.8 (v/v/v). The lipid phase was collected and dried under a stream of $\mathrm{N}_{2}$ at $37^{\circ} \mathrm{C}$. After dissolving the dry sample in $1 \mathrm{ml}$ chloroform, the solution was transferred to silicic acid columns. The columns were washed sequentially with chloroform, acetone and methanol; the methanol fraction which contains the PLFAs was collected. After alkaline methanolysis, the organic phase was collected in dichloromethane, and hexane methylnonadecanoate (C19:0) was added as internal standard to each sample. The PLFAs were separated and analysed in a GC-FID (HP 6890); for more information see Chowdhury et al.(2011a). The following signature PLFAs were used as indicators for specific microbial groups: bacteria (14:0, 15:0, 16:0, 17:0, a17:0), Gram-positive bacteria (10 me16:0, i15:0, a15:0, i16:0, i17:0), Gram-

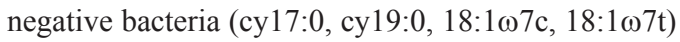

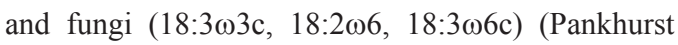
al., 2001; Zak et al., 2000). The sum of signature fatty acids for a certain microbial group was used to calculate biomass of that group, the fungi to bacteria $(\mathrm{F} / \mathrm{B})$ ratio was calculated by dividing fungal biomass by bacterial biomass. 


\subsection{Statistical analysis}

There were three replicates per treatment in both experiments. In Experiment 1, the data of cumulative respiration at the end of the experiment was analysed by two-way ANOVA (analysis of variance) with $\mathrm{C}$ treatment (glucose and cellulose mixtures) and $\mathrm{EC}$ as fixed factors. Microbial biomass $\mathrm{C}$ was assessed by three way ANOVA (C treatment $\mathrm{x}$ EC $\mathrm{x}$ day). In Experiment 2, the data of cumulative respiration and microbial biomass $\mathrm{C}$ were assessed by three-way ANOVA (treatment $x$ time $x$ EC). Bacterial and fungal biomass and the F/B ratio were analysed by two-way ANOVA at given time (day 0 and 42) (treatment $x$ EC). Tukey test was used to determine significant differences (GenStat ${ }^{\circledR}$ for Windows 14.0, VSN Int. Ltd, UK, 2010). Microbial community composition was analysed by Primer-E software (Primer-E Ltd, Plymouth Marine Laboratory, Plymouth, UK). The PLFA data was transformed using $\log (\mathrm{x}+1)$ and plotted using non- metric multi- dimensional scaling (MDS) plot. Significant differences in microbial community composition among the treatments were determined by Permanova $(\mathrm{P} \leq 0.1)$.

\section{Results}

3.1 Experiment 1 (different proportions of glucose and cellulose)

\subsubsection{Cumulative respiration}

Addition of $5 \mathrm{~g} \mathrm{C} \mathrm{kg}^{-1}$ significantly increased cumulative respiration compared to the unamended control (Figure 1). In the amended soils, cumulative respiration was highest with $100 \%$ glucose and lowest with $100 \%$ cellulose. Mixing glucose with cellulose increased cumulative respiration compared to $100 \%$ cellulose, but the effect of the proportion of glucose varied with soil salinity. In the nonsaline soil, cumulative respiration in the treatments with mixes of glucose and cellulose was about $25 \%$ higher than with $100 \%$ cellulose irrespective of the proportion of glucose. At EC11, cumulative respiration in the combined treatments was about $25 \%$ higher than with $100 \%$ cellulose when $20 \%$ of the $\mathrm{C}$ was added as glucose whereas with lower proportions of glucose, respiration did not differ significantly from that of $100 \%$ cellulose. At EC43, cumulative respiration increased with increasing proportion of glucose in the mixed treatments when the glucose proportion was $>2.5 \%$. With $100 \%$ glucose, cumulative respiration was significantly lower than in the non-saline soil only at EC43. With $100 \%$ cellulose and all combined treatments, cumulative respiration was significantly lower than in the non-saline soil at EC11 and EC43. Cumulative respiration did not differ between EC11 and EC43 with $100 \%$ cellulose, but decreased significantly in the mixed treatments except with $10 \%$ glucose. Based on the assumption that only the added $\mathrm{C}$ was respired and there was no priming effect (Kuzyakov et al., 2000), it can be calculated that with $100 \%$ glucose, all added $\mathrm{C}$ was respired by the end of the experiment at all salinity levels. When glucose was combined with cellulose, the proportion of added $\mathrm{C}$ respired was $80 \%$ in the non-saline soil and $50 \%$ in the saline soils. With cellulose alone, $60 \%$ of the added $\mathrm{C}$ was respired in the non-saline soil, and 35\% in the saline soils. 


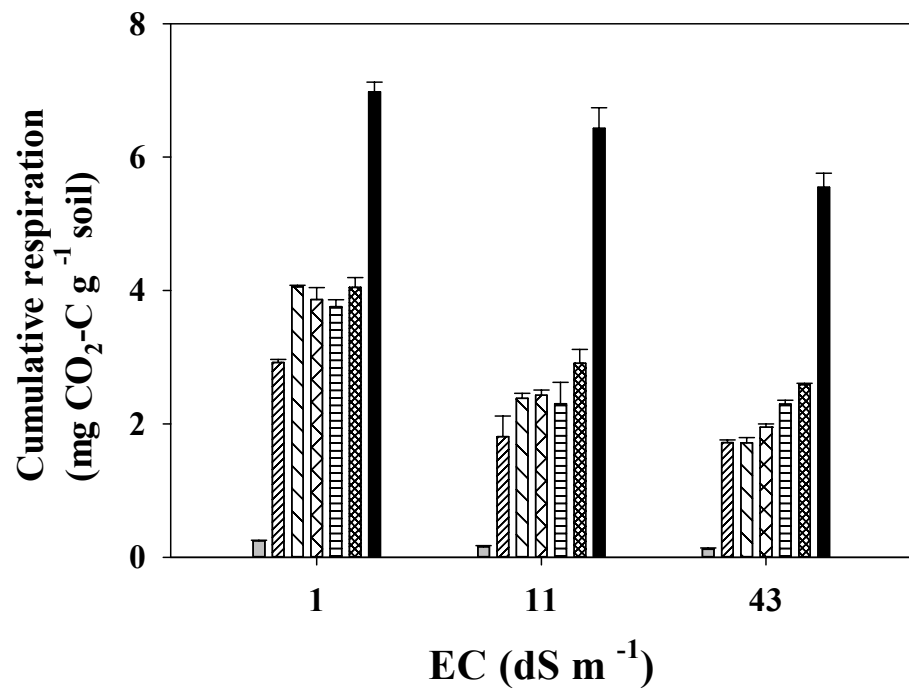

Ratios of glucose (G) and cellulose $(\mathrm{Ce})$

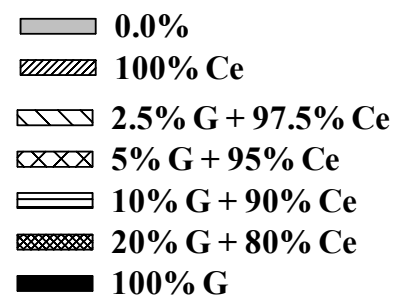




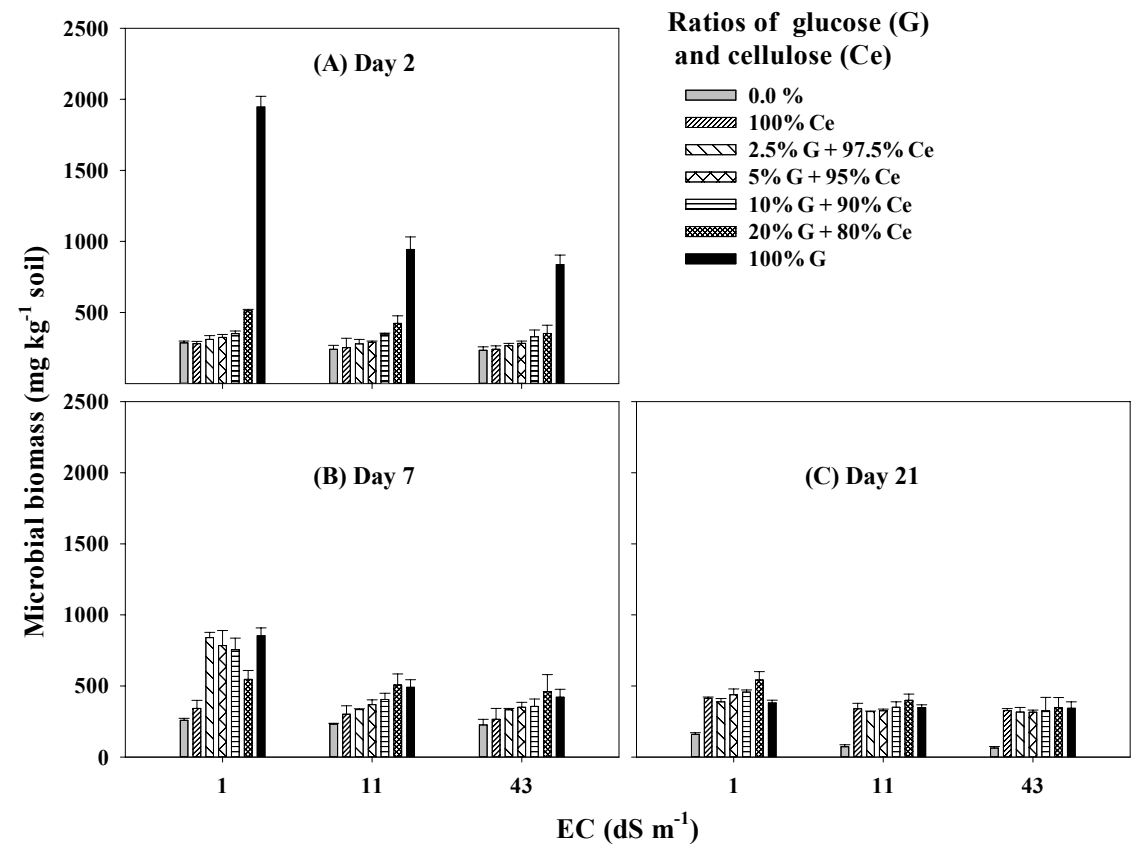

Figure 2. Microbial biomass C concentration on days 2 (A) 7 (B) and 21 (C) in soils with ECe1, 11 and $43 \mathrm{dS}^{-1} \mathrm{amended}$ with $5 \mathrm{~g} \mathrm{~kg}^{-1}$ at different ratios of glucose $(\mathrm{G})$ and cellulose $(\mathrm{Ce}): 0,100 \% \mathrm{Ce}, 2.5 \% \mathrm{G}+97.5 \% \mathrm{Ce}, 5 \% \mathrm{G}+95 \% \mathrm{Ce}, 10 \% \mathrm{G}+90 \% \mathrm{Ce}$, $20 \% \mathrm{G}+80 \% \mathrm{Ce}, 100 \% \mathrm{G}, 100 \% \mathrm{Ce}(\mathrm{n}=3$, vertical lines indicate standard error). Thick vertical line in panel (a) shows LSD based on the $\mathrm{C}$ treatment $\mathrm{x}$ salinity $\mathrm{x}$ sampling date interaction.

\subsection{Experiment 2 (change of $C$ form over time)}

\subsubsection{Cumulative respiration}

Cumulative respiration was lower in the unamended than the amended soils (Figure 3). In the amended soils where the $\mathrm{C}$ form changed over time, cumulative respiration over 14 days after $\mathrm{C}$ addition was always lower with cellulose than glucose. The effect of salinity on cumulative respiration over 14 days depended on $\mathrm{C}$ form, treatment and period (days $0-14,15-28$ or 29-42). Cumulative respiration from day 0 to 14 decreased with increasing EC in all amended treatments. When $\mathrm{C}$ was added as cellulose every 2 weeks (treatment $\mathrm{Ce}+\mathrm{Ce}+\mathrm{Ce}$ ), cumulative respiration significantly increased over time at all EC levels. The increase in cumulative respiration from period day 0-14 to period day 29-42 was greatest in the most saline soil: 2-fold in the nonsaline soil (EC0.6), 5-fold at EC12.5 and 24-fold at EC37.4 (Figure 3B). In this treatment, the effect of salinity on cumulative respiration changed over time. Cumulative respiration in the first period (day 0-14) decreased significantly with increasing EC, in the second period (day 15-28) it decreased significantly only from EC12.5 to EC37.4. However, cumulative 
respiration in the third period (day 29-42) was not influenced by EC. In the treatment where glucose was added every 2 weeks $(\mathrm{G}+\mathrm{G}+\mathrm{G})$ (Fig. 3C), cumulative respiration was greatest in the first period (day 0-14) in the non-saline soil whereas it greatest in the third period (day 29-42) in the soil with EC37.4. Increasing salinity significantly reduced cumulative respiration in the first period (day $0-14$ ), but had no significant effect in the later periods. In the treatment where cellulose was added at the start of the first and second period followed by glucose in the start of the third period $(\mathrm{Ce}+\mathrm{Ce}+\mathrm{G})$ (Figure 3D), cumulative respiration over 14 days significantly increased with each period. Compared to the first period, cumulative respiration in the third period was increased 2-fold at EC0.6, 13-fold at EC12.5 and 29-fold at EC37.4. Cumulative respiration decreased with increasing EC in the first period, but was reduced only at the highest EC in the second period. Salinity had no effect on cumulative respiration in the third period. When glucose was supplied in the first period and cellulose in the second and third periods $(\mathrm{G}+\mathrm{Ce}+\mathrm{Ce})$ (Figure 3E), cumulative respiration at EC0.6 and EC12.5 was similar in the first (day 0-14) and third period (day 29-42), but lower in the second period (day 15-28). At EC37.4, cumulative respiration was lower in the second and third period than in the first period. Compared to the non-saline soil, cumulative respiration in the first and third period was significantly reduced only at EC37.4 whereas in the second period, it was not significantly influenced by salinity. In the treatment where glucose was added at the start of the first and third period and cellulose in the second period $(\mathrm{G}+\mathrm{Ce}+\mathrm{G})$ (Figure
$3 \mathrm{~F})$, cumulative respiration was highest in the third period (day 29-42) and lowest in the second period (day 15-28). In the first period compared to EC0.6, cumulative respiration was significantly lower at EC37.4. But salinity had no significant effect on cumulative respiration in the second and third period. In the treatment where cellulose was added at the start of the first (day 0-14) and the third period (day 29-42) and glucose was added in the second period $(\mathrm{Ce}+\mathrm{G}+\mathrm{Ce})$ (Figure $3 \mathrm{G})$, cumulative respiration was highest in the second period and lowest in the first period. Compared to the non-saline soil, cumulative respiration decreased with increasing EC in the first period. However, in the second period (day15-28) salinity had no effect on cumulative respiration and in the third period it was significantly reduced only at EC37.4.

The amount of $\mathrm{C}$ remaining at the end of each period was calculated by subtracting the $\mathrm{C}$ respired during the period from the $\mathrm{C}$ added at the start of that period (Table 2) assuming no measurable priming effect. At the end of experiment, all added $\mathrm{C}$ was respired in the treatment where only glucose was added $(\mathrm{G}+\mathrm{G}+\mathrm{G})$ at all salinity levels. This was also the case at EC0.6 and 12.5 in the treatment where glucose was added twice $(\mathrm{G}+\mathrm{Ce}+\mathrm{G})$, but some of the added $\mathrm{C}$ remained at EC37.4. In the treatments where $\mathrm{C}$ was added as cellulose twice or three times, the amount of $\mathrm{C}$ remaining at the end of the experiment increased with increasing EC. In the periods when cellulose was added, the amount of $\mathrm{C}$ remaining was greatest when it was added in the first period at all salinity levels. Negative values indicate that in a given period, more $\mathrm{C}$ was respired than added. 
Table 2. Amount of remaining $C$ at the end of a given period of $C$ added at the start of the period (days $0,15,29)$ in soils with ECe $0.6,12.5$ and $37.4 \mathrm{dS} \mathrm{m}^{-1}$ amended with cellulose $(\mathrm{Ce})$ or glucose $(\mathrm{G})$. Negative values indicate that more $\mathrm{C}$ was respired than added in a given period. The sum of remaining $\mathrm{C}$ was calculated by adding the amounts remaining in the three periods.

\begin{tabular}{|c|c|c|c|c|c|}
\hline \multirow[t]{3}{*}{ Treatment } & \multirow[t]{3}{*}{$\mathrm{EC}$} & \multicolumn{4}{|c|}{ Remaining $\mathrm{C}\left(\mathrm{g} \mathrm{kg}^{-1}\right)$} \\
\hline & & \multicolumn{3}{|c|}{ Period (day) } & \multirow{2}{*}{$\begin{array}{l}\text { Sum of remaining } \\
\qquad \mathrm{C}\left(\mathrm{g} \mathrm{kg}^{-1}\right)\end{array}$} \\
\hline & & $0-14$ & $15-28$ & $29-42$ & \\
\hline \multirow[t]{3}{*}{$\mathrm{Ce}+\mathrm{Ce}+\mathrm{Ce}$} & 0.6 & 0.63 & 0.054 & -0.58 & 0.10 \\
\hline & 12.5 & 1.23 & 0.29 & -0.07 & 1.45 \\
\hline & 37.4 & 1.43 & 1.08 & -0.24 & 2.27 \\
\hline \multirow[t]{3}{*}{$\mathrm{G}+\mathrm{G}+\mathrm{G}$} & 0.6 & 0 & 0 & 0 & 0 \\
\hline & 12.5 & 0 & 0 & 0 & 0 \\
\hline & 37.4 & 0.44 & -0.21 & -0.23 & 0 \\
\hline \multirow[t]{3}{*}{$\mathrm{Ce}+\mathrm{Ce}+\mathrm{G}$} & 0.6 & 0.56 & 0.14 & -1.02 & 0 \\
\hline & 12.5 & 1.31 & 0.18 & -1.08 & 0.41 \\
\hline & 37.4 & 1.43 & 1.22 & -0.49 & 2.17 \\
\hline \multirow[t]{3}{*}{$\mathrm{G}+\mathrm{Ce}+\mathrm{Ce}$} & 0.6 & 0 & 0.43 & -0.35 & 0.08 \\
\hline & 12.5 & 0 & 0.90 & 0.26 & 1.16 \\
\hline & 37.4 & 0.44 & 1.03 & 1.03 & 2.51 \\
\hline \multirow[t]{3}{*}{$\mathrm{G}+\mathrm{Ce}+\mathrm{G}$} & 0.6 & 0 & 0.61 & -0.61 & 0 \\
\hline & 12.5 & 0 & 0.77 & -0.77 & 0 \\
\hline & 37.4 & 0.44 & 1.04 & -0.41 & 1.07 \\
\hline \multirow[t]{3}{*}{$\mathrm{Ce}+\mathrm{G}+\mathrm{Ce}$} & 0.6 & 0.58 & -0.64 & 0.11 & 0.06 \\
\hline & 12.5 & 1.23 & -0.41 & 0.32 & 1.96 \\
\hline & 37.4 & 1.41 & -0.12 & 0.94 & 2.23 \\
\hline
\end{tabular}

\subsection{Microbial biomass $C$}

At all EC levels, addition of $\mathrm{C}$ increased the MBC concentration at the end of each period (days 14, 28 and 42) compared to the unamended control (Figure 4). In most $\mathrm{C}$ treatments, the $\mathrm{MBC}$ concentration on days 14 , 28 and 42 was lowest at EC37.4. The exceptions were treatments where glucose was added once at the start of the first or the third period $(\mathrm{Ce}+\mathrm{Ce}+\mathrm{G} ; \mathrm{G}+\mathrm{Ce}+\mathrm{Ce})$. In these treatments, the $\mathrm{MBC}$ concentration on day 42 did not differ between EC0.6 and EC37.4. When cellulose was added in each period $(\mathrm{Ce}+\mathrm{Ce}+\mathrm{Ce})$, the $\mathrm{MBC}$ concentration was highest on day 42 in $\mathrm{EC} 0.6$, lowest on day 28 in EC37.4, but did not change over time in EC12.5 (Figure 4B). At all three sampling dates, the $\mathrm{MBC}$ concentration was lowest in EC37.4. When glucose was added in each period $(\mathrm{G}+\mathrm{G}+\mathrm{G})$ or once at the start of the third period $(\mathrm{Ce}+\mathrm{Ce}+\mathrm{G})$ (Figure 4C, 4D), the $\mathrm{MBC}$ concentration at all sampling dates was highest with EC12.5 and lowest with EC37.4. This was also true for days 14 and 28 in the treatment where glucose was added at the start of the first period $(\mathrm{G}+\mathrm{Ce}+\mathrm{Ce})$ (Figure $4 \mathrm{E})$. In treatments where the $\mathrm{C}$ form was changed twice $(\mathrm{G}+\mathrm{Ce}+\mathrm{G}$ and $\mathrm{Ce}+\mathrm{G}+\mathrm{Ce}$ ) (Figure $4 \mathrm{~F}, 4 \mathrm{G})$, the $\mathrm{MBC}$ concentration was lowest with EC37.4 at all sampling dates. In treatment $\mathrm{G}+\mathrm{Ce}+\mathrm{G}$ (Figure $4 \mathrm{~F}$ ), the $\mathrm{MBC}$ concentration did not change significantly over time. But in treatment $\mathrm{Ce}+\mathrm{G}+\mathrm{Ce}$, the $\mathrm{MBC}$ concentration was lowest on day 28 ( 2 weeks after addition of glucose) in EC0.6 and EC12.5.

On day 42 , bacterial and fungal biomass did not differ significantly among EC levels (Table 3), except for a higher bacterial and fungal biomass compared to the unamended soil at EC12.5 and EC37.4 in treatment $\mathrm{Ce}+\mathrm{G}+\mathrm{Ce}$. The $\mathrm{F} / \mathrm{B}$ ratio did not differ significantly among EC levels. 


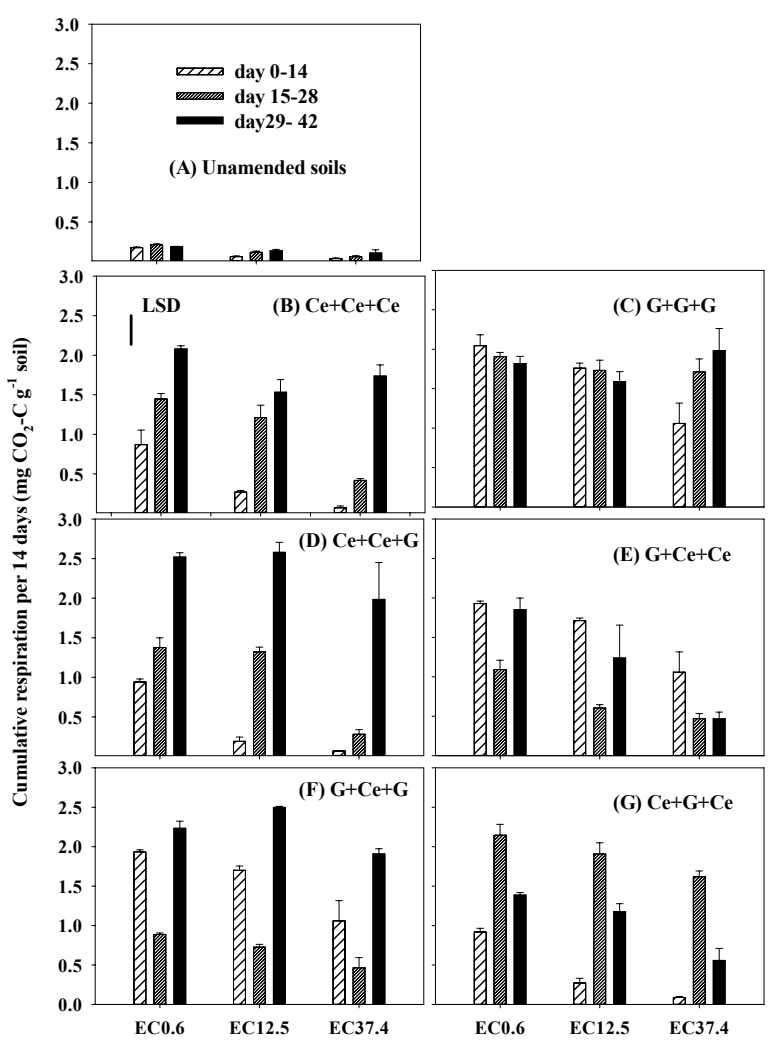

Figure 3. Cumulative respiration in the 2-week periods day 0-14, day15-28 and day 29-42 in soils with ECe0.6, 12.5 and $37.4 \mathrm{dS}$ m-1 in the unamended control or amended at the start of each period with cellulose (Ce) or glucose $(\mathrm{G})$ bars represent standard error $(n=3)$. Thick vertical line in panel $(B)$ shows LSD based on the $\mathrm{C}$ treatment $\mathrm{x}$ salinity $\mathrm{x}$ period interaction.

Table 3. Biomass of bacteria and fungi and fungi/ bacteria ratios based on PLFAsat the end of the experiment (day 42) in soils with ECe $0.6,12.5$ and $37.4 \mathrm{dS}$ m-1amended with cellulose $(\mathrm{Ce})$ or glucose $(\mathrm{G})(\mathrm{n}=3)$, different letters indicate significant differences $(p \leq 0.05)$.

\begin{tabular}{|c|c|c|c|c|c|c|c|c|c|c|c|c|c|c|c|c|c|c|}
\hline \multirow[t]{2}{*}{ Treatments } & \multicolumn{6}{|c|}{ Bacterial biomass } & \multicolumn{6}{|c|}{ Fungal biomass } & \multicolumn{6}{|c|}{$\mathrm{F} / \mathrm{B}$ ratio } \\
\hline & EC0.6 & & EC12.5 & & EC37.4 & & EC0.6 & & EC12.5 & & EC37.4 & & EC0.6 & & EC12.5 & & EC37.4 & \\
\hline unamended & 9.89 & $\mathrm{ab}$ & 5.64 & $\mathrm{a}$ & 12.22 & $a b c$ & 5.18 & $\mathrm{ab}$ & 4.51 & $\mathrm{a}$ & 7.2 & $a b c$ & 0.56 & $a b c$ & 0.81 & $\mathrm{bc}$ & 0.59 & $a b c$ \\
\hline $\mathrm{Ce}+\mathrm{Ce}+\mathrm{Ce}$ & 32.02 & bcd & 27.82 & abcd & 26.65 & abcd & 19.68 & d & 18.33 & $\mathrm{~cd}$ & 16.48 & abcd & 0.62 & $a b c$ & 0.70 & $a b c$ & 0.63 & $a b c$ \\
\hline $\mathrm{Ce}+\mathrm{Ce}+\mathrm{G}$ & 17.38 & abcd & 31.24 & bcd & 22.82 & abcd & 10.79 & abcd & 22.95 & d & 11.75 & abcd & 0.63 & $a b c$ & 0.74 & $a b c$ & 0.51 & $a b c$ \\
\hline $\mathrm{G}+\mathrm{Ce}+\mathrm{Ce}$ & 28.28 & abcd & 23.92 & abcd & 23.45 & abcd & 18.06 & $\mathrm{~cd}$ & 17.63 & bcd & 11.04 & abcd & 0.64 & $a b c$ & 0.79 & $\mathrm{bc}$ & 0.48 & $a b$ \\
\hline $\mathrm{G}+\mathrm{Ce}+\mathrm{G}$ & 23.28 & abcd & 17.97 & abcd & 34.47 & $\mathrm{~cd}$ & 15.66 & abcd & 13.85 & abcd & 20.13 & d & 0.69 & $a b c$ & 0.81 & $\mathrm{bc}$ & 0.59 & $a b c$ \\
\hline
\end{tabular}




\subsubsection{Microbial community structure}

On day 0 microbial community composition based on PLFA did not differ among EC levels (data not shown). Microbial community structure at the end of the experiment (day 42), was plotted using multi-dimensional scaling (Figure 5). Permanova showed that microbial community structure differed significantly between EC0.6 and EC37.4 in all C treatments, except in $\mathrm{G}+\mathrm{Ce}+\mathrm{G}$ (Table 4). Microbial community structure differed significantly between EC0.6 and EC12.5 only in $\mathrm{Ce}+\mathrm{Ce}+\mathrm{G}$ and $\mathrm{Ce}+\mathrm{G}+\mathrm{Ce}$. Microbial community structure differed between EC12.5 and EC37.4 in four of the seven treatments but not in treatments where cellulose was added twice or three times $(\mathrm{Ce}+\mathrm{Ce}+\mathrm{Ce}, \mathrm{Ce}+\mathrm{Ce}+\mathrm{G}, \mathrm{G}+\mathrm{Ce}+\mathrm{Ce})$.
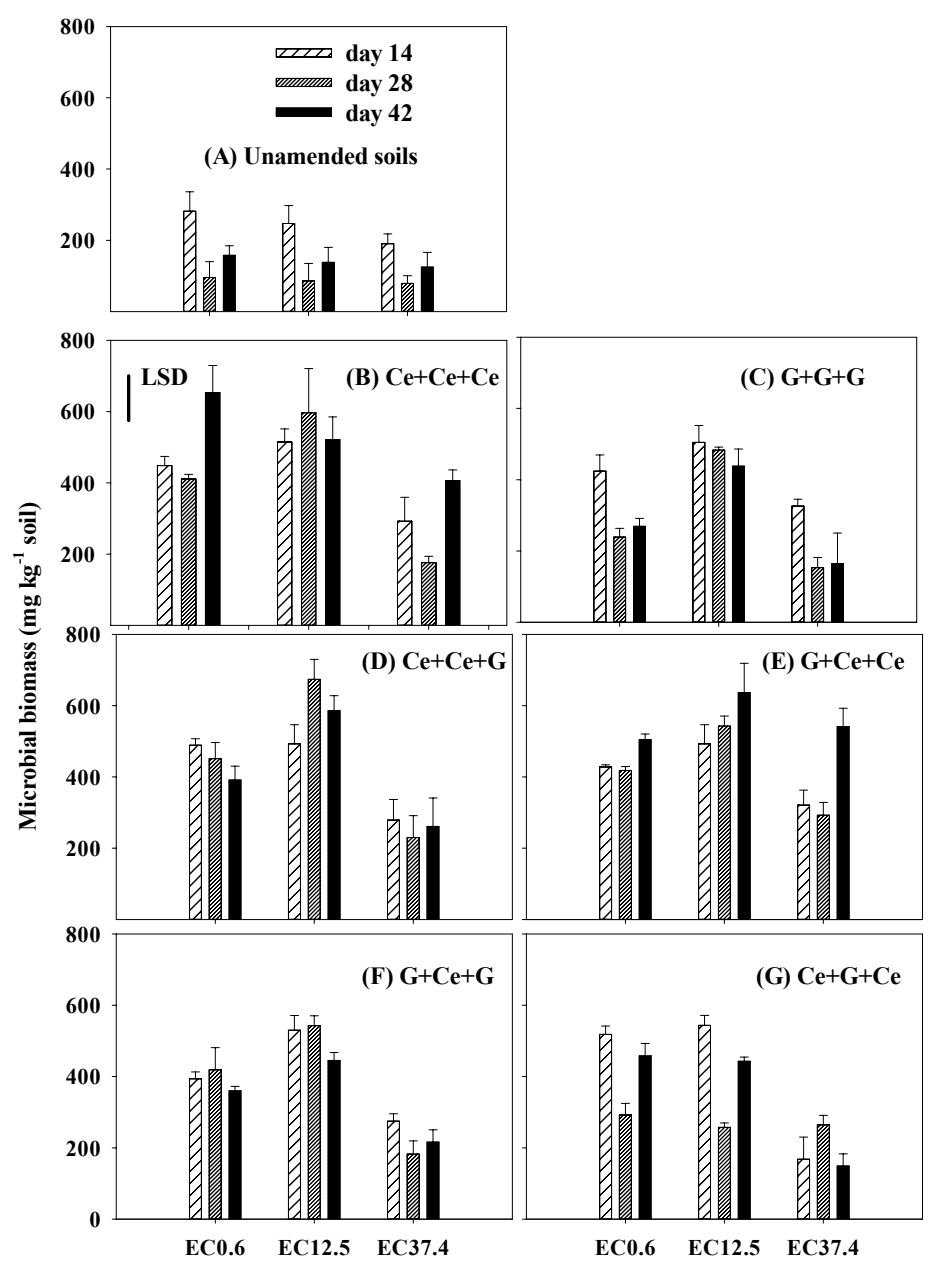

Figure 4. Microbial biomass C on days 14, 28 and 42 in soils with different ECe0.6, 12.5 and 37.4 dS m-1 in the unamended control or amended at the start of each period with cellulose $(\mathrm{Ce})$ or glucose $(\mathrm{G})$ bars represent standard error $(\mathrm{n}=3)$. Thick vertical line in panel (B) shows LSD based on the $\mathrm{C}$ treatment $\mathrm{x}$ salinity $\mathrm{x}$ period interaction. 
Table 4. Results of Permanova for microbial community structure on day 42 based on PLFA for pair-wise comparison between EC levels in different $\mathrm{C}$ treatments.

\begin{tabular}{|c|c|c|c|c|c|c|c|}
\hline Pair wise & & & Treatment & & & & \\
\hline EC & unamended & $\mathrm{Ce}+\mathrm{Ce}+\mathrm{Ce}$ & $\mathrm{G}+\mathrm{G}+\mathrm{G}$ & $\mathrm{Ce}+\mathrm{Ce}+\mathrm{G}$ & $\mathrm{G}+\mathrm{Ce}+\mathrm{Ce}$ & $\mathrm{G}+\mathrm{Ce}+\mathrm{G}$ & $\mathrm{Ce}+\mathrm{G}+\mathrm{Ce}$ \\
\hline $\begin{array}{c}0.6 \text { and } \\
12.5\end{array}$ & ns & $\mathrm{ns}$ & ns & $*$ & ns & ns & $*$ \\
\hline $\begin{array}{c}0.6 \text { and } \\
37.4\end{array}$ & $*$ & * & $*$ & * & $*$ & ns & $*$ \\
\hline $\begin{array}{c}12.5 \text { and } \\
37.4\end{array}$ & $*$ & ns & $*$ & ns & ns & $*$ & $*$ \\
\hline
\end{tabular}

Asterisks indicates significant differences $(P \leq 0.1)$ between community structure of a given EC pair, (ns) not significant

\section{Discussion}

The results of the two experiments confirmed our earlier study (Elmajdoub and Marschner 2013) that the response of soil microbes to salinity depends on the form in which $\mathrm{C}$ is supplied. However the experiments presented here also show that this response is modulated by the proportion of glucose and cellulose and may change if $\mathrm{C}$ is added repeatedly in different $\mathrm{C}$ forms.

Addition of glucose induced higher cumulative respiration than addition of cellulose in both experiments. This can be explained by the high availability of glucose compared to cellulose and the fact that glucose can be rapidly utilised by most soil microbes. Cellulose utilisation on the other hand requires the synthesis and release of cellulase which can be carried out by fewer microbes and is more energy-demanding than glucose uptake (de Boer et al. 2005; Killham 1994). The differences in microbial community structure based on PLFAs between the treatments with only cellulose compared to only glucose addition show that continuous supply of a single $\mathrm{C}$ sources changes community structure. However, the lower activity and different community structure with cellulose supply does not seem to limit the ability to utilise glucose when it was added to soils that received cellulose in the previous period in Experiment 2. Cumulative respiration was high at the end of each glucose period where glucose was added even when respiration was low in the previous period with cellulose supply.

The high $\mathrm{C}$ availability after glucose addition is also evident in the high MBC concentration on day 2 in the first experiment. However, the rapid decline in MBC concentration from day 2 to day 7 shows that a large proportion of the biomass dies when this easily available $\mathrm{C}$ is depleted. Our calculations of the amount of $\mathrm{C}$ remaining 2 weeks after $\mathrm{C}$ addition in Experiment 2 (Table 2) confirm that all $\mathrm{C}$ added as 
glucose is respired in soils with low or medium salinity. Utilisation of the added $\mathrm{C}$ is slower with cellulose, which is evident in the greater amount of added $\mathrm{C}$ remaining after 2 weeks in Experiment 2. Further slow cellulose decomposition can explain the slower build-up of microbial biomass in Experiment 1 where the MBC concentration increased from day 2 to day 7 and then remained stable.

Cumulative respiration in Experiment 1 did not decrease from EC11 to EC43 in the treatment with $100 \%$ cellulose but decreased significantly in the glucose-cellulose mixes except with $10 \%$ glucose. This suggests that small amounts of readily available C may make microbes more susceptible to high EC compared to microbes supplied with cellulose only. Mixing glucose and cellulose increased microbial growth particularly from day 2 to day 7 compared to $100 \%$ cellulose. Fast growing microbes have been shown to be more sensitive to stress than slowgrowing ones (Schimel et al., 2007; Van Gestel et al., 1993). Hence, our first hypothesis (microbial activity and biomass will decrease more rapidly with salinity compared to glucose alone as the proportion of glucose decreases, becoming similar to that with cellulose alone) has to be declined because the relationship between glucose percentage and adaptation to salinity is more complex.

In agreement with our previous study (Elmajdoub and Marschner, 2013), cumulative respiration with a single addition of only glucose was reduced compared to the non-saline soil at the highest EC but not at the medium EC. With a single addition of cellulose on the other hand, cumulative respiration was already reduced significantly at the medium EC and did not decrease further at the highest EC. This suggests that microbes supplied with an easily available $\mathrm{C}$ source (glucose) can maintain a higher activity at medium EC compared to non-saline soils than those supplied with a poorly decomposable $\mathrm{C}$ source (cellulose). Synthesis of osmolytes which is an important mechanism to counteract the high osmotic stress in saline soils is very energy-demanding (Oren, 1999). The fast decomposition of glucose is likely to generate the energy for rapid osmolytes synthesis to withstand the medium EC. However, the results of the second experiment show that the effect of $\mathrm{C}$ source can change with repeated $\mathrm{C}$ addition. Only in the first period, cumulative respiration was reduced more strongly at medium EC compared to non-saline soil with cellulose supply than with glucose addition. When glucose was added after cellulose at the start of the second or third period, cumulative respiration was not influenced by EC. On the other hand, cumulative respiration was lower at the highest EC compared to the non-saline soil when cellulose had been added in the period before or when cellulose was added after glucose. Thus, addition of an easily available $\mathrm{C}$ source after cellulose appears to increase microbial tolerance to high salinity. This seems to be in contrast to the first experiment where mixing a small proportion of glucose to cellulose increased sensitivity to salinity compared to $100 \%$ cellulose. This apparent contradiction may be explained by the response of the microbial community at the time at which glucose is available. As mentioned above, a small proportion of glucose present at the start is likely to have increased growth of fast-growing microbes which became more susceptible to salinity when $\mathrm{C}$ availability was low. With cellulose on the other hand, $\mathrm{C}$ supply is low but remains at this level for longer because it is decomposed slowly. In the second experiment, the addition of glucose after cellulose may also have induced growth of fastgrowing microbes but will also enhance the growth of the more slowly growing cellulose decomposers which were dominating the active community. Further, $\mathrm{C}$ depletion after glucose addition is unlikely to have occurred because there was a residual amount of $\mathrm{C}$ from the previous cellulose addition. 
The importance of high C supply for salinity tolerance was shown in the second experiment in the treatments where only glucose or cellulose was added three times. After three additions of $1.5 \mathrm{~g} \mathrm{C}$ as glucose or cellulose, cumulative respiration was similar at all EC levels. However, after a single addition cumulative respiration decreased with increasing EC. The increased tolerance after $\mathrm{C}$ had been added three times occurred in most amended treatments in Experiment 2 except for those with cellulose added at the start of the third period. This confirmed only the first part of our second hypothesis (compared to a single addition, the reduction of respiration by salinity will be smaller with repeated $\mathrm{C}$ addition due to increasing $\mathrm{C}$ supply), but not the second part (irrespective of the form in which $\mathrm{C}$ is supplied glucose or cellulose). Cumulative respiration always increased when the $\mathrm{C}$ form was changed from cellulose to glucose and salinity had no or only a small effect on respiration. This may indicate priming (Kuzyakov et al., 2000), that is, glucose addition enhanced utilisation of cellulose C. However, the switch from glucose to cellulose reduced cumulative respiration compared to glucose supply. Therefore, our third hypothesis (microbial activity will be little affected by medium salinity when glucose is added whereas it will be reduced with cellulose addition) is true only for the first addition. In later periods, the response of cumulative respiration to salinity was not only influenced by the $\mathrm{C}$ form added at the start of a period, but also by the $\mathrm{C}$ form in the previous period.

The finding that salinity influenced cumulative respiration more strongly than microbial biomass $\mathrm{C}$ is in agreement with our previous studies (Elmajdoub and Marschner, 2013; Yan and Marschner, 2012) and can be explained by the fact that cumulative respiration integrates microbial response over a given period whereas $\mathrm{MBC}$ concentration is just a snap shot of the biomass at the time of sampling.
Microbial community structure based on PLFA data differed significantly between the non-saline soil and EC37.4 in most $\mathrm{C}$ treatments which is agreement with previous studies that also report that salinity alters microbial community structure (Chowdhury et al., 2011a; Pankhurst et al., 2001). This experiment further showed that at a given EC, microbial community structure is also influenced by the form in which $\mathrm{C}$ added in the three periods.

\section{Conclusion}

Mixing small amounts of readily available $\mathrm{C}$ (glucose) with poorly available C (cellulose) increased microbial activity and growth. However, the increased growth induced by small amounts of glucose also appears to make microbes more susceptible to negative impact of salinity compared to $100 \%$ cellulose. The second experiment showed that irrespective of $\mathrm{C}$ form added, salinity had a smaller negative impact on respiration when $\mathrm{C}$ was added repeatedly compared to a single addition. This suggests that high and repeated $\mathrm{C}$ supply increases tolerance of microbes to salinity. However, repeated addition of $\mathrm{C}$ to soils may be too costly to be feasible in the field. Carbon supply in the rhizosphere is higher than in the bulk soil (Dennis et al. 2010). Therefore, growing salinity-tolerant plants is likely to be an economical way to improve microbial activity and thereby soil fertility.

\section{Acknowledgements}

The senior author thanks the Libyan government for the postgraduate scholarship. 


\section{References}

Anderson, J.M., Ingram, J.S.I. 1993. Tropical soil biology and fertility: a handbook of methods. CAB International.

Butterly, C.R., Marschner, P., McNeill, A.M., Baldock, J.A. 2010. Rewetting $\mathrm{CO}_{2}$ pulses in Australian agricultural soils and the influence of soil properties. Biol. Fertil Soils. 46, 739-753.

Chowdhury, N., Marschner, P., Burns, R. 2011a. Response of microbial activity and community structure to decreasing soil osmotic and matric potential. Plant Soil. 344, 241-254.

Chowdhury, N., Nakatani, A.S., Setia, R., Marschner, P. 2011b. Microbial activity and community composition in saline and non-saline soils exposed to multiple drying and rewetting events. Plant Soil. 348, 103-113.

de Boer, W.., Folman, L.B., Summerbell, R.C., Boddy, L. 2005. Living in a fungal world: impact of fungi on soil bacterial niche development. FEMS. Microbiol Rev. 29, 795-811.

De Nobili, M., Contin, M., Mondini, C., Brookes, P. 2001. Soil microbial biomass is triggered into activity by trace amounts of substrate. Soil Biol. Biochem. 33, 1163-1170.

Dennis, P.G., Miller, A.J., Hirsch, P.R. 2010. Are root exudates more important than other sources of rhizodeposits in structuring rhizosphere bacterial communities?. FEMS Microbiol. Ecol. 72, 313327.

Elmajdoub, B., Marschner, P. 2013. Salinity reduces the ability of soil microbes to utilise cellulose. Biol. Fertil. Soils. 49, 379-386.

Frostegård, Å., Bååth, E., Tunlio, A. 1993. Shifts in the structure of soil microbial communities in limed forests as revealed by phospholipid fatty acid analysis. Soil Biol. Biochem. 25, 723-730.
Hagemann, M., 2011. Molecular biology of cyanobacterial salt acclimation. FEMS. Microbiol Rev. 35, 87-123.

Kahlaoui, B., Hachicha, M., Rejeb, S., Rejeb, M.N., Hanchi, B., Misle, E. 2011. Effects of saline water on tomato under subsurface drip irrigation. J. Soil Sci. Plant Nutr. 11, 69 - 86. Killham, K. 1994. Soil ecology. Cambridge University Press, Cambridge.

Klados, E., Tzortzakis, N. 2014. Effects of substrate and salinity in hydroponically grown Cichorium spinosum. J. Soil Sci. Plant Nutr. 14, 211-222.

Kuzyakov, Y., Friedel, J., Stahr, K. 2000. Review of mechanisms and quantification of priming effects. Soil Biol. Biochem. 32, 1485-1498.

Martinez-Beltran, J., Manzur, C.L. 2005.Overview of Salinity Problems in the World and FAO Strategies to Address the Problem. Proceedings of the International Salinity Forum, Riverside, California, pp. 311-313.

Muhammad, S., Müller, T., Joergensen, R. 2006. Decomposition of pea and maize straw in Pakistani soils along a gradient in salinity. Biol. Fertil. Soils. 43, 93-101.

Munns, R., Tester, M. 2008. Mechanisms of salinity tolerance. Annu. Rev. Plant Biol. 59, 651-681.

Nelson, D.R., Mele, P.M. 2007. Subtle changes in rhizosphere microbial community structure in response to increased boron and sodium chloride concentrations. Soil Biol. Biochem. 39, 340-351.

Oren, A. 1999. Bioenergetic aspects of halophilism. Microbiol. Mol Biol R. 63, 334-348.

Oren, A. 2001. The bioenergetic basis for the decrease in metabolic diversity at increasing salt concentrations: implications for the functioning of salt lake ecosystems. Hydrobiologia. 466, 61-72. 
Pankhurst, C., Yu, S., Hawke, B., Harch, B. 2001. Capacity of fatty acid profiles and substrate utilization patterns to describe differences in soil microbial communities associated with increased salinity or alkalinity at three locations in South Australia. Biol Fertil Soils. 33, 204-217.

Rayment, G., Higginson, F. 1992. Australian laboratory handbook of soil and water chemical methods. Inkata Press Pty Ltd, Sydney, Australia.

Rengasamy, P. 2006. Soil salinity and sodicity, In: D. Stevens (ed). Growing crops with reclaimed wastewater. CSIRO Publishing, Collingwood, Australia, pp. 125-138.

Schimel, J., Balser, T.C., Wallenstein, M. 2007. Microbial stress-response physiology and its implications for ecosystem function. Ecol. 88, 1386-1394.

Setia, R., Marschner, P., Baldock, J., Chittleborough, D. 2010. Is $\mathrm{CO}_{2}$ evolution in saline soils affected by an osmotic effect and calcium carbonate? Biol. Fertil Soils. 46, 781-792.

Setia, R., Smith, P., Marschner, P., Baldock, J., Chittleborough, D.J., Smith, J. 2011. Introducing a decomposition rate modifier in the Rothamsted carbon model to predict soil organic carbon stocks in saline soils. Environ. Science. Technol. 45, 6396-6403.

Shainberg, I., Letey, J. 1984. Response of soils to sodic and saline conditions. Hilgardia. 52, 1-57.
Sylvia, D.M., Fuhrmann, J.J., Hartel, P., Zuberer, D.A. 2005. Principles and applications of soil microbiology. Pearson Prentice Hall New Jersey.

Tripathi, S., Kumari, S., Chakraborty, A., Gupta, A., Chakrabarti, K., Bandyapadhyay, B.K. 2006. Microbial biomass and its activities in saltaffected coastal soils. Biol. Fertil Soils. 42, 273277.

Van Gestel, M., Merckx, R., Vlassak, K. 1993. Microbial biomass responses to soil drying and rewetting: the fate of fast-and slow-growing microorganisms in soils from different climates. Soil Biol. Biochem. 25, 109-123.

Vance, E., Brookes, P., Jenkinson, D. 1987. An extraction method for measuring soil microbial biomass C. Soil Biol. Biochem. 19, 703-707.

Wichern, J., Wichern, F., Joergensen, R.G. 2006. Impact of salinity on soil microbial communities and the decomposition of maize in acidic soils. Geoderma. 137, 100-108.

Yan, N., Marschner, P. 2012. Response of microbial activity and biomass to increasing salinity depends on the final salinity, not the original salinity. Soil Biol. Biochem. 53, 50-55.

Zak, D.R., Pregitzer, K.S., Curtis, P.S., Holmes, W.E. 2000. Atmospheric $\mathrm{CO}_{2}$ and the composition and function of soil microbial communities. Ecol. Appl. 10, 47-59. 